\title{
Vorhang auf für die neue Webseite
}

\begin{abstract}
Alle medizinischen Fachzeitschriften des Wissenschaftsverlages Springer Wien haben seit kurzem einen gemeinsamen Internetauftritt. Für alle Nutzer steht damit eine reichhaltige, multidisziplinäre Recherche-Plattform zur Verfügung.
\end{abstract}

www.SpringerMedOnline.at bietet den Nutzern zahlreiche Vorteile: Auf der neuen Website werden im Sinne von „Multi- und Interdisziplinarität" die Inhalte aus vielen Fachbereichen online verknüpft. Unter den digitalisierten Zeitschriften sind die Wochenzeitung Ärzte Woche für niedergelassene Ärzte ebenso zu finden wie die traditionsreiche Wiener Klinische Wochenschrift, die im vergangenen Jahr ihr 120-jähriges Bestehen feierte. Der österreichische Zweig des global operierenden Wissenschaftsverlages Springer möchte damit seine Stellung als eine der wichtigsten Anlaufstellen für medizinische Professionisten weiter ausbauen.

\section{Optimierte Recherche}

Zwar greifen Angehörige der Gesundheitsberufe derzeit noch vor allem zu den gedruckten Ausgaben ihrer Zeitschriften, die Internetnutzung legt jedoch massiv zu insbesondere bei Recherchetätigkeiten. Daher stand bei der Konzeption der neuen Springer-Seite der Zugang zur Suchfunktion, deren Funktionalität und einfache Handhabung ganz oben auf der Liste der Prioritäten. Daher wurde die Suchleiste bei www.SpringerMedOnline.at unübersehbar auf der ersten Seite positioniert (Abb.). Die Recherche selbst funktioniert nach den bewährten Prinzipien der großen Suchmaschinen (Tipp zur Suchanleitung: www.suchfibel.de). Auch Jahrgang, Thema oder Zeitschrift können konkret berücksichtigt werden.

Einen weiteren Schwerpunkt legten die Web-Architekten auf eine gute Manövrieroberfläche ohne technische Spielereien, die das Ladetempo nur unnötig verlängern würden. Hier wurde, wie bei anderen Internetseiten der globalen Springer-Familie, auf Übersicht und Funktionalität gesetzt. Definiertes Ziel: Mit möglichst wenigen Klicks soll der Nutzer ohne Umwege bei den für ihn

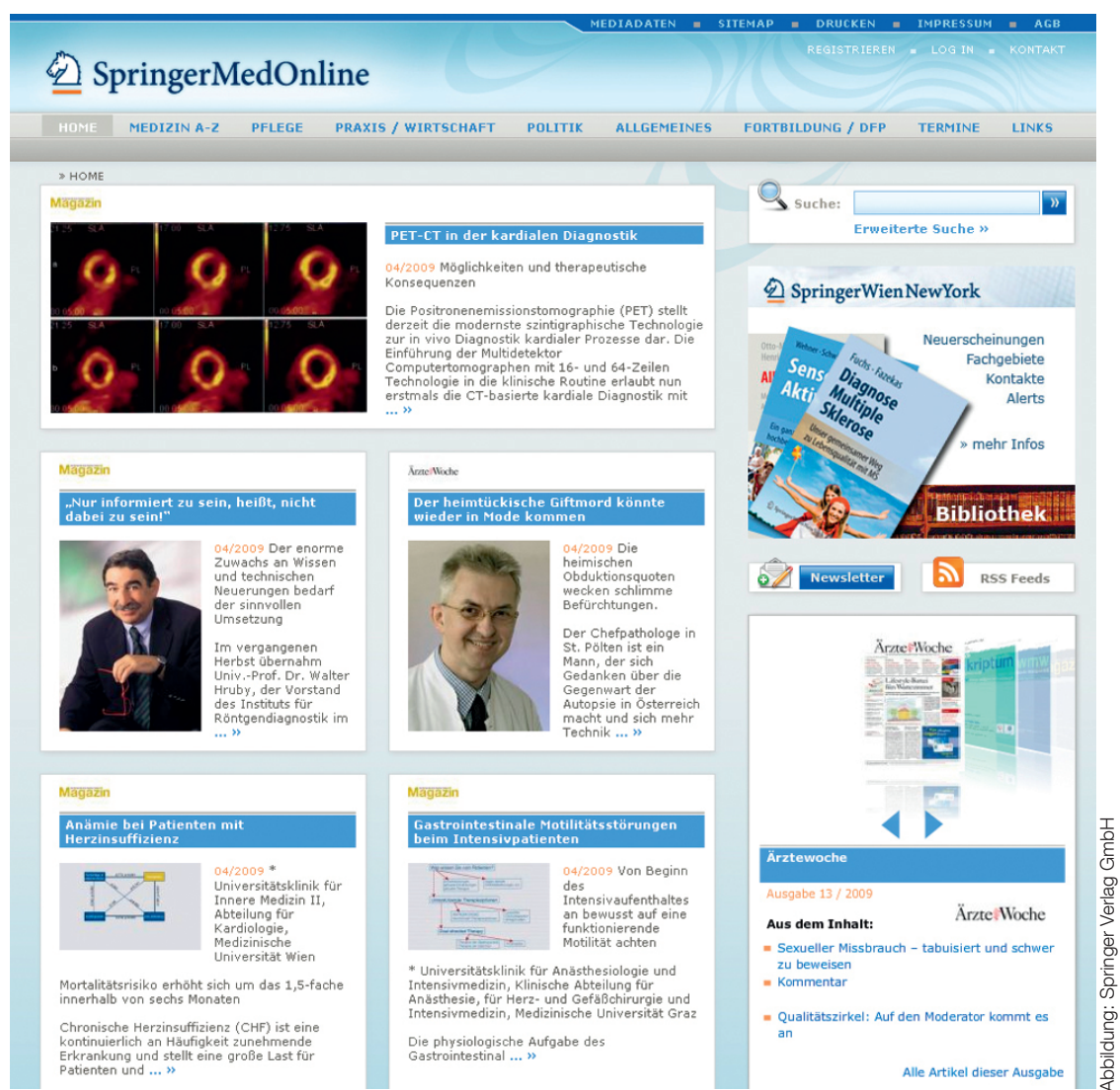

Dank der freundlichen Farben und der schlichten Eleganz wird selbst ein längeres Verweilen auf der Seite kein Martyrium für die Augen.

relevanten Informationen landen. Das heißt freilich nicht, dass die neue Webseite nur Internet-Puritaner bedienen will. Auch Nutzer mit Zeit, die sich bummelnd und schmökernd durch das Internet bewegen, werden mit dem neuen Web-Auftritt des Wiener Springer-Verlages ihre Freude haben. Denn dank der freundlichen Farben und der schlichten Eleganz wird selbst ein längeres Verweilen auf der Seite kein Martyrium für die Augen.

Wer die gesamte Vielfalt der neuen Springer-Homepage sehen möchte, sollte sich kostenlos und verpflichtungsfrei registrieren. Bei dieser Gelegenheit kann auch der wöchentlich erscheinende Newsletter abonniert werden. Aus rechtlichen Gründen bleibt die Registrierung auf www.SpringerMedOnline.at/registrieren/ - die nur wenige Minuten in Anspruch nimmt - nur Fachkrei- sen vorbehalten. Dazu zählen Ärzte, Zahnärzte, Apotheker, medizinisches Personal, Angestellte pharmazeutischer Unternehmen, Medizinjournalisten und Studenten der Medizin sowie Pharmazie. Jedoch können auch Nicht-Abonnenten auf einen großen Teil der Themen zugreifen.

Die Registrierung bietet allerdings einen Vorteil: Die dynamische Oberfläche passt sich den Interessen des Benutzers an. So bekommt jeder bevorzugt Themen aus seinem Tätigkeitsgebiet präsentiert. Darüber hinaus macht der News-Ticker den Seitenbenutzer auf alle wichtigen Themen - auch abseits des eigenen Ressorts aufmerksam. Weiters werden tausende im Springer-Verlag Wien erschienene Artikel aus den vergangenen Jahren in die neue Webseite integriert und hier archiviert. Raoul Mazhar 